\title{
Perioperative fluid management in kidney transplantation: a black box
}

\author{
Maria Helena Calixto Fernandes ${ }^{1 *}$, Thomas Schricker ${ }^{1}$, Sheldon Magder ${ }^{2}$ and Roupen Hatzakorzian ${ }^{1,2}$
}

\begin{abstract}
The incidence of delayed graft function in patients undergoing kidney transplantation remains significant. Optimal fluid therapy has been shown to decrease delayed graft function after renal transplantation. Traditionally, the perioperative volume infusion regimen in this patient population has been guided by central venous pressure as an estimation of the patient's volume status and mean arterial pressure, but this is based on sparse evidence from mostly retrospective observational studies. Excessive volume infusion to the point of no further fluid responsiveness can damage the endothelial glycocalyx and is no longer considered to be the best approach. However, achievement of adequate flow to maintain sufficient tissue perfusion without maximization of cardiac filling remains a challenge. Novel minimally invasive technologies seem to reliably assess volume responsiveness, heart function and perfusion adequacy. Prospective comparative clinical studies are required to better understand the use of dynamic analyses of flow parameters for adequate fluid management in kidney transplant recipients. We review perioperative fluid assessment techniques and discuss conventional and novel monitoring strategies in the kidney transplant recipient.
\end{abstract}

Keywords: Fluid management, Kidney transplantation, Delayed graft function, Perioperative volume infusion, Intravascular fluid assessment, Fluid responsiveness

\section{Background}

Despite improvements in outcomes for patients undergoing renal transplantation, delayed graft function (DGF) remains a significant complication and is a predictor of the subsequent clinical course [1]. Delayed graft function is associated with decreased graft and patient survival, impaired long-term function and increased acute rejection $[2,3]$. Optimized perioperative hemodynamic management is effective for prevention of DGF $[4,5]$, but optimal fluid therapy remains a challenge.

The kidneys receive approximately $25 \%$ of the body's total cardiac output $(\mathrm{CO})$ and are essential for maintaining tonicity of body fluids and for adjusting extracellular volume. Patients with renal failure often have electrolyte imbalances and tend to oscillate between hypovolemia and hypervolemia [6]. This results in a very narrow margin of safety for intravenous fluid resuscitation and maintenance. Patients undergoing kidney transplantation

\footnotetext{
* Correspondence: mariahelena3@hotmail.com

'Department of Anesthesia, Royal Victoria Hospital, 1001 Decarie Blvd,

Montreal, QC H4A 3J1, Canada

Full list of author information is available at the end of the article
}

are at risk of developing DGF, acute kidney injury (AKI) and fluid overload. Hypovolemia can lead to further kidney injury, but excessive fluid therapy can result in pulmonary edema. Optimal fluid management is essential to reduce perioperative complications.

Central venous pressure (CVP)-guided volume infusion is the traditional approach in renal transplantation $[7,8]$ and involves intraoperative infusion of large volumes of fluid. Maximal volume infusion to the point of no further fluid responsiveness has long been considered the best approach [9-11], but this can lead to excess fluid which can damage the endothelial glycocalyx and lead to a fluid shift into the interstitial space [12]. Furthermore, in this range, $\mathrm{CO}$ cannot be modified when needed by changes in cardiac filling pressure alone.

Previous studies on the assessment of intravascular volume and optimization of $\mathrm{CO}$ and renal blood flow have indicated that conventional monitoring provides insufficient data for adequate fluid management [13-16]. However, meta-analyses of randomized controlled trials indicate that approaches which include measurement of $\mathrm{CO}$ and calculate oxygen delivery to guide intravenous 
fluid replacement are associated with decreased mortality and postoperative complications [17-19].

In this article, we review perioperative fluid assessment techniques and discuss conventional and novel monitoring strategies in this challenging patient population.

\section{Main text}

\section{Delayed graft function}

The definition of DGF is not consistent in the literature. At least 18 different heterogeneous criteria were identified in a systematic review [20]. Delayed graft function is most commonly used to describe the failure of the transplanted kidney to function promptly after transplantation, leading to dialysis within 1 week after transplant $[20,21]$.

The reported incidence of DGF varies from 2 to $70 \%$ in deceased kidney transplants [22, 23], not surprising given the wide range of definition. Outcomes are best in living donor transplantation, in which rates are $4-10 \%$ [23]. Despite improvement in transplantation techniques, the incidence of DGF has not decreased. A possible explanation may be the increasing number of grafts from expanded criteria donors and nonheart-beating donations [23, 24].

The underlying pathophysiology of DGF can be donor, recipient or surgeon related and can be due to hemodynamic (ischemic-reperfusion) or immunological (particularly T-lymphocyte) processes. A key factor is occult imbalance between oxygen delivery and consumption in the graft [25].

Acute tubular necrosis (ATN) is the most common cause of DGF. Acute tubular necrosis can be already present at the time of organ procurement if the deceased donor's kidney is injured. Prolonged warm and cold ischemia time, as well as the manner of preservation, also can lead to ATN [23]. Acute tubular necrosis of the transplanted kidney can be diagnosed initially by nuclear renal scan which shows gradual uptake but minimal or no excretion of the tracer [26]. The hemodynamic status of the recipient during renal transplantation, the time following kidney implantation and completion of the anastomosis, and reperfusion injury all can effect graft perfusion [27] and the development of DGF $[4,5,28]$. Furthermore, the transplanted kidney is denervated and lacks neurogenic regulation of renal blood flow [29]. The vasodilation caused by mediators that accumulate during the ischemia period, and the increase in vascular permeability, might contribute to the invariable decline in CVP, from the operating room to the postanesthesia care unit [30]. Continuous monitoring is therefore highly recommended in postoperative care.

Several epidemiological studies in different patient populations have confirmed an association between stages of AKI and short-term and long-term outcomes [31-33] as well as the independent association of AKI with higher mortality risk [34]. This is likely also true in kidney transplantation. Once the donated kidney has reached the implantation unit, donor and graft characteristics are no longer modifiable, and hemodynamic management becomes an adjustable portion of the process (Fig. 1).

In summary, DGF is predominantly caused by ATN. Adequate perfusion of the transplanted kidney is required, but to date no specific therapeutic intervention has reduced the incidence of ATN and recovery [35]. The role of health care professionals involved in perioperative fluid management of kidney transplantation is to identify the perfect balance of fluid therapy.

\section{Perioperative intravascular fluid assessment}

The assessment of a patient's intravascular volume for achievement of appropriate fluid management is a major challenge for the clinician and has been shown to improve postoperative outcomes [12]. Understanding of the following four definitions is essential in perioperative care:

1. Euvolemia: a state in which the vascular volume is adequate for filling of the heart and maintenance of an appropriate $\mathrm{CO}$ to generate the appropriate oxygen supply for tissue needs.

2. Fluid responsiveness: a state in which an increase in vascular volume increases the stroke volume (SV) and CO. The notion of fluid responsiveness does not necessarily mean that the patient will benefit from or need fluid therapy. Parameters of perfusion should guide the decision to assess the fluid response rather than responsiveness in a compromised patient.

3. Fluid overload: a state in which excessive accumulation of fluid in the vascular system is caused by excessive parenteral infusion or deficiencies in cardiovascular or renal fluid volume regulation.

4. Hypovolemia: a state in which effective circulatory volume is decreased and there is insufficient oxygen delivery to tissues, possibly resulting in organ dysfunction.

Despite a clear definition, there is no gold standard for the diagnosis and treatment of hypovolemia. Both acute and chronic conditions interact with fluid homeostasis, and medical history must always be considered. Progressive loss of renal function results in various adaptive and compensatory changes to maintain homeostasis with glomerular filtration rates below $10 \mathrm{ml} / \mathrm{min}$, and these abnormalities typically have clinical consequences. A patient with end-stage renal disease has a disturbed acid-base and electrolyte balance and compromised hemodynamic autoregulation. Inflammatory mediators can alter renal 


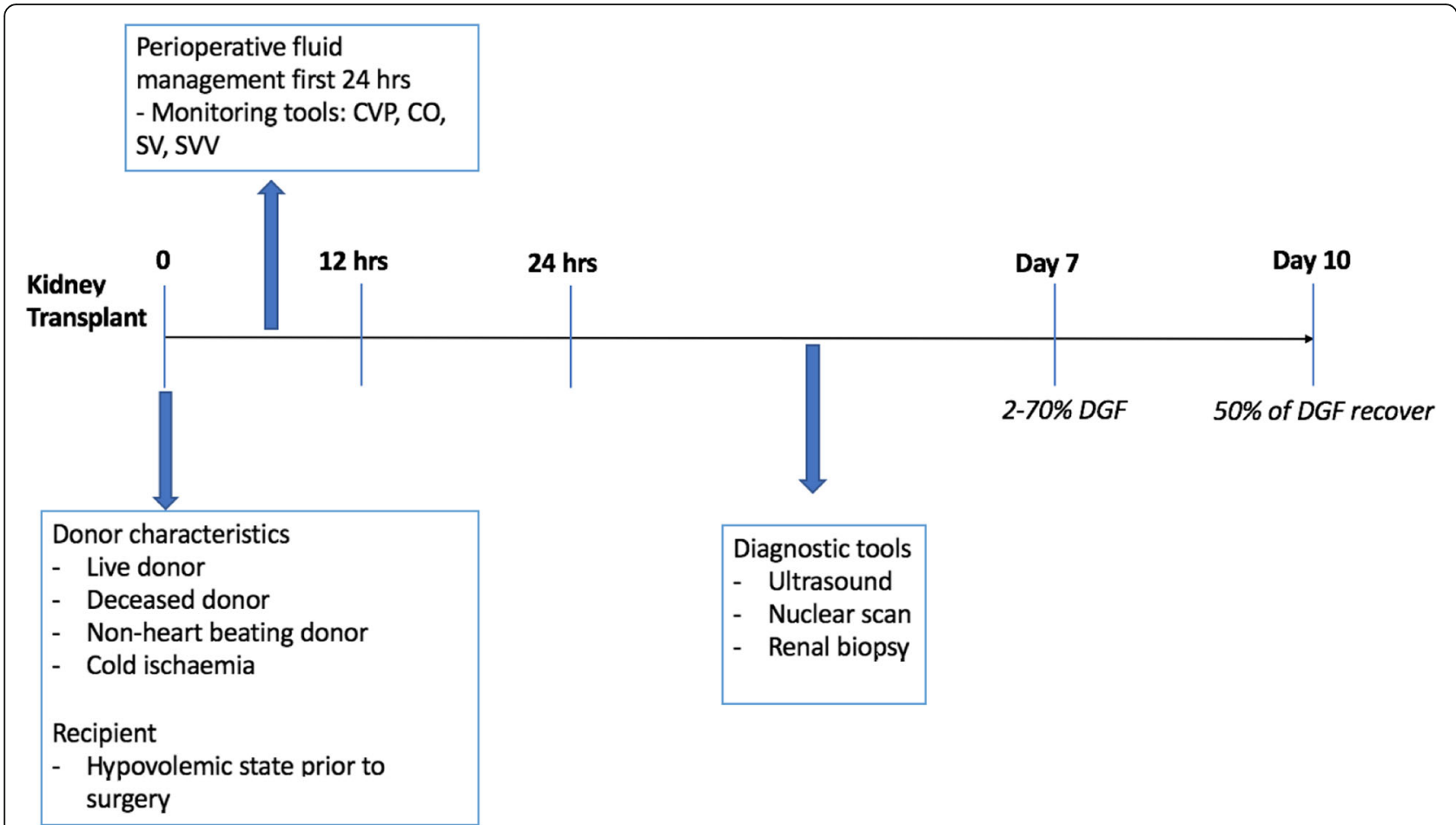

Fig. 1 Kidney transplantation and DGF: timeline for risk factors and interventions. DGF delayed graft function, CVP central venous pressure, CO cardiac output, SV stoke volume, SW stroke volume variation

hemodynamics and cause glomerular, tubular and interstitial damage, if uncontrolled [36].

In addition to the uncertainty associated with the patient's volume state, appropriate targets remain unclear. To determine which monitoring method provides the most accurate information in the context of kidney transplantation, and which target to rely on, we will review previously implemented methods, their advantages and disadvantages, and their relative utility in predicting fluid responsiveness and tissue perfusion. Methods range from conventional techniques such as clinical history and physical examination, measurement of blood pressure (BP), heart rate (HR), urine output (UOP), CVP and pulmonary artery pressure (PAP), to novel technologies such as echocardiography, cardiorespiratory interactions and dynamic analyses of flow parameters.

\section{Conventional monitoring and targets}

Clinical experience and use of traditional parameters such as BP, HR, UOP, CVP [37] and PAP to guide perioperative fluid therapy in kidney transplantation have been shown to be unreliable.

Hypovolemia in the perioperative setting often can be misdiagnosed clinically [38] due to a lack of obvious fluid loss in the context of altered systemic vascular resistance associated with capillary leak. An observational study in healthy volunteers during progressive hemorrhage showed that blood loss of $25 \%$ can appear with minimal clinical impacts on BP and HR, despite worsening microcirculatory flow [39]. Hypotension is not present in all patients in shock. If the physician waits for hypotension to start treating hypovolemia, tissue hypoxia will already be present [40].

In the case of hypovolemia and hypoperfusion, physiological compensatory mechanisms can maintain effective vascular volume and perfusion by increasing the vascular retention of an infused volume and decreasing vascular capacitance. Plasma levels of renin and aldosterone increase and atrial natriuretic factor decreases, followed by arterioconstriction which decreases precapillary hydrostatic pressure and filtration [41, 42]. A $30-50 \%$ reduction in glomerular filtration, and an increase in fluid reabsorption from the interstitial space, can also help avoid tissue edema $[42,43]$. These compensatory mechanisms are highly compromised in end-stage renal disease and in the postischemic kidney.

Blood pressure is the most commonly used vital parameter for organ perfusion, and functions as an indirect measurement of renal perfusion in clinical practice. Although classic physiological studies suggest that autoregulation of renal blood flow is maintained at lower levels of mean arterial pressure (MAP $50-60 \mathrm{mmHg}$ ) [44, 45], retrospective data suggest that intraoperative $\mathrm{MAP}<55$ $\mathrm{mmHg}$ is associated with AKI and myocardial injury 
[46]. In a prospective randomized controlled trial in which MAP targets of $65-70 \mathrm{mmHg}$ were compared to MAP targets of $80-85 \mathrm{mmHg}$ in septic patients, there were no significant differences in mortality [47]. Renal replacement therapy was less commonly required in patients with chronic hypertension whose MAP was maintained at values of $\geq 80 \mathrm{mmHg}$ [47]. However, raising MAP by increasing the systemic vascular resistance does not necessarily improve flow and potentially also not renal perfusion.

Given the expected large oscillations in hemodynamic parameters during kidney transplantation, invasive arterial BP monitoring is commonly used. In a recent study of the biochemical outcomes of renal transplant recipients, no difference was observed in the creatinine levels of patients with a MAP between 95 and $131 \mathrm{mmHg}$, but MAP was continuously maintained at $>95 \mathrm{mmHg}$ via the judicious use of fluids and dopamine [27]. Consistent with other studies, Campos et al. [4] observed that MAP $<93 \mathrm{mmHg}$ is associated with poor graft function. In an earlier study, Tóth et al. [11] observed stable creatinine levels in patients with a MAP of $80-100 \mathrm{mmHg}$, but an increase in creatinine in patients with $\mathrm{MAP}<80 \mathrm{mmHg}$. However, these associations do not imply that raising pressure would restore function. The optimal measurement to evaluate renal microcirculation is unclear, as well as it being unknown which individual MAP could prevent AKI during different medical conditions.

Earlier studies have indicated that the magnitude of $\mathrm{UO}$ is one of the most clinically used predictors for graft function immediately after reperfusion [48] and proposed the use of CVP and PAP values to predict diuresis $[8,10]$. Although aggressive volume expansion to a target CVP of 10-15 mmHg [49] and PAP > $20 \mathrm{mmHg}$ [10] at the time of reperfusion were associated with improved renal blood flow and better graft outcomes, targeting these values was not recommended by other authors. A twofold greater risk of kidney dysfunction was observed with CVP $\geq 11 \mathrm{mmHg}$ [4]. Overinfusion can lead to tissue edema with decreased tissue oxygenation [50] and subjects vulnerable patients to complications such as pulmonary edema, infections, myocardial ischemia, ileus, compromised renal flow, renal injury and even increased mortality $[4,12,51-53]$.

A decrease in CVP in the post-transplant period is observed in a majority of kidney recipients, independent of their intravascular fluid status [30], but this does not mean the patient needs fluid. The etiology is unclear, but might be related to increased vascular permeability or the release of vasodilator mediators during the ischemic period. An increase in vascular capacitance also could be a factor [54]. Overemphasis on CVP as a goal can lead to excess infusion of fluid and increased capillary leakage, which can promote further fluid administration.
Use of pulmonary artery catheters has fallen out of favor due to concerns about complications such as pulmonary embolism among high-risk patients [55], pulmonary artery rupture [56] and cardiac perforation [57], and a frequent misinterpretation of the waveforms [58].

Static cardiac filling pressures such as CVP and PAP correlate poorly with the intravascular volume and are notoriously unreliable in predicting accurate fluid responsiveness compared to dynamic parameters $[59,60]$. In a recent meta-analysis of the correlation between CVP and changes in cardiac performance, Marik and Cavallazzi [15] showed that only $57 \%$ of high-risk patients in the intensive care unit and operating room who appeared to be hypovolemic based on CVP were fluid responders, whereas the other half were unnecessarily loaded with fluids. However, a high CVP could potentially compromise renal flow, particularly when the arterial pressure is low.

Thus, the CVP should not be used alone to guide fluid responsiveness [15] and should not be a target for clinical decisions regarding fluid management [61]. Although the conventional parameters discussed previously are relevant to the hemodynamic assessment, none are good predictors of fluid responsiveness [59], which has prompted a search for alternative methods. There currently is increasing use of measurement of $\mathrm{CO}$ and SV with the aid of less invasive and easier to use devices. Use of these novel technologies to guide therapy is becoming vital in modern medical practice.

\section{Physiological background for a novel approach to fluid administration}

The primary goal in the perioperative setting is to avoid tissue hypoxia, the major cause of organ dysfunction. Traditional indicators can be normal in the presence of tissue hypoxia and cannot be used to predict an imbalance between oxygen demand and consumption, particularly if they are not interpreted in the context of perfusion markers such as $\mathrm{CO}$, lactates and central venous saturation [13-15, 61].

Sufficient oxygenation and tissue perfusion are crucial for all metabolic needs of cells and are based on hemoglobin concentration, arterial oxygen content and CO. Therefore, the percent change in any one of these three variables equally alters oxygen delivery, with $\mathrm{CO}$ usually having the largest changes [62]. As CO is the product of $\mathrm{SV}$ and $\mathrm{HR}$, it can also be influenced by changes in preload, contractility and afterload. A mismatch between tissue needs and oxygen delivery leads to tachycardia and hypotension in most patients. Thus, an increase in preload with fluid therapy is only one part of treatment. An increase in contractility with inotropes remains the only therapeutic option when cardiac function is volume limited [62]. 
According to Frank-Starling's law of the heart, administering fluids can increase the preload and thereby increase SV and CO. Under physiological conditions, both ventricles work on the ascending portion of the FrankStarling curve, and afterload, contractility and HR are assumed to remain constant during the volume infusion [63]. This mechanism represents the functional preload reserve for the heart under stress conditions. If the patient is a fluid responder, this mechanism translates to a shift to the right of the venous return curve relative to the cardiac function curve and intersects it on the steep part of the cardiac function at a higher value [64]. A patient is considered a fluid responder when SV increases by at least $10-15 \%$ in response to volume expansion [65]. However, when the venous return intersects the flat part of the cardiac function curve there is no increase in $\mathrm{CO}$ and there even can be a decrease in ventricular performance and an increase in tissue edema and consequent tissue dysoxia. In nonresponders, $\mathrm{CO}$ only can rise by an increase in contractility or HR. The change in CVP in response to a fluid bolus can help interpret what happened with the fluid bolus when used in combination with the $\mathrm{CO}$ response.

Among the many devices and monitors currently available for measuring cardiac function and output, we will review the intraoperative use of transesophageal echocardiography (TEE) and emphasize the utility of noninvasive devices that calculate reliable trends in $\mathrm{CO}$ and dynamic indices based on simple physiology.

\section{Transesophageal echocardiography}

Transesophageal echocardiography can be a useful diagnostic tool for evaluating right and left heart function, potential outflow tract obstruction and the presence of a pericardial effusion. It also can be used to obtain Doppler measurements of CO. However, TEE is operator dependent, and errors in the measurement of the diameter of the left ventricular outflow tract skew results. Presence of an irregular HR also affects the final calculation of CO.

Use of intraoperative TEE on renal allograft outcomes has only been evaluated in one study, in which living donor renal transplants were examined. Guiding fluid therapy in 110 patients by corrected flow time obtained with continuous transesophageal Doppler (TED) monitoring did not improve immediate graft function compared to fluid administration guided by CVP. However, significantly less fluid was used in the TED-monitored group, and the incidence of postoperative complications related to fluid overload was reduced [66].

Transesophageal eechocardiography does not permit continuous monitoring for instantaneous evaluation of fluid responsiveness. Transesophageal echocardiography is also time consuming and expensive, and requires intensive operator training. Careful attention must be given to the limitations of the assessment of CO by TEE, which may be beyond the level of expertise of a physician with only moderate experience. New studies with more robust data are required to support the use of TEE for fluid management in this patient population.

\section{Noninvasive dynamic CO technology}

Cardiac output alone can be a poor predictor of fluid responsiveness, although its response to a preloadmodifying maneuver such as mechanical ventilation can provide useful information about fluid responsiveness without the administration of fluid [67].

Currently there are several noninvasive $\mathrm{CO}$ monitoring technologies including pulse contour analysis (PCA), pulse wave transit time, thoracic electrical bioimpedance/bioreactance and $\mathrm{CO}_{2}$ rebreathing [68]. We will focus on parameters derived from technology using PCA to calculate $\mathrm{CO}$. The $\mathrm{SV}$ is derived from the arterial waveform signal using the area under the systolic part of the arterial pressure curve. There are few devices using PCA technology: FloTrac/Vigileo/EV1000 system (Edwards Lifesciences, Irvine, CA, USA), LiDCOrapid (LiDCO, Cambridge, UK), MostCare (Vygon, Vytech, Padua, Italy) and ProAQT/PulsioFlex (Pulsion/ MAQUET, Rastatt, Germany). Although the absolute $\mathrm{CO}$ values may not be as accurate as those derived by pulmonary artery catheter, these devices are very useful in providing acceptable trending abilities to follow changes in $\mathrm{CO}$ and SV. More studies are warranted to determine the effectiveness of these devices in improving patient outcomes [69].

Dynamic variation of arterial waveform-derived parameters (i.e., systolic pressure variation (SPV), pulse pressure variation (PPV) and stroke volume variation $(\mathrm{SVV})$ ) in mechanically ventilated patients provides a precise indication of fluid responsiveness, particularly when compared to static indices [59]. However, SPV, PPV and SVV only can predict variations in the stroke volume index and cardiac index when the patient receives controlled ventilation and has no spontaneous respiratory efforts (Fig. 2). The percentages by which both parameters are likely to increase can also be predicted.

The fundamentals underlying these parameters are based on simple physiology and are well represented in the Frank-Starling curve (Fig. 3). The cyclic positivepressure ventilation intermittently increases pleural pressure and alters the filling conditions of the left and right ventricles. The increase in pleural pressure decreases venous return and right ventricle (RV) preload. Additionally, the RV afterload can increase due to an inspiratory rise in transpulmonary pressure. The decrease in the RV preload and the increase in the RV afterload decrease the RV SV, with minimum values reached end- 


\section{Dynamic variation of arterial waveform-derived parameters}

$\mathrm{PPV}=$ pulse pressure variation

$\mathrm{SPV}=$ systolic pressure variation

$\mathrm{SVV}=$ stroke volume variation

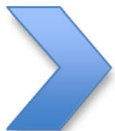

Mechanically ventilated patient

Dynamic measures such as PPV, SPV, SVV are more accurate than static measurements for assessing fluid responsiveness in mechanically ventilated patients

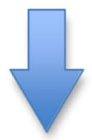

\section{Devices used for dynamic measurement based on the arterial waveform}

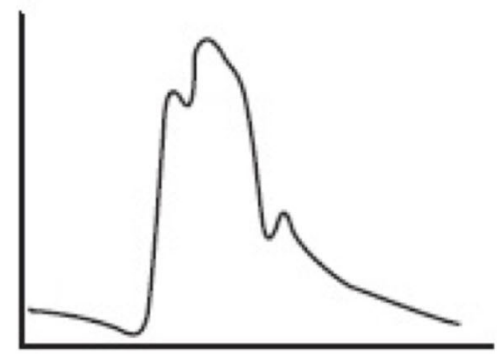

FloTrac/Vigileo

LiDCOrapid

MostCare

ProAQT/PulsioFlex

Fig. 2 Dynamic parameters derived from the arterial waveform and available technologies

inspiratory. The inspiratory reduction in the RV ejection will in a few beats decrease left ventricle (LV) preload and SV. The respiratory changes in the LV SV indicate a biventricular preload dependence and only occur in the ascending portion of the Frank-Starling curve [70].

Dynamic analyses of flow parameters need to be restricted to patients under controlled mechanical ventilation with tidal volumes between 8 and $10 \mathrm{ml} / \mathrm{kg}$ ideal body weight because heart-lung interactions are more complicated with spontaneous breathing efforts with or without a ventilator [71]. When right ventricular insufficiency is present, an experimental study of anesthetized pigs indicated that PPV and SVV only can be used to assess volume responsiveness during a volume-loading maneuver [72].

The use of PPV may be preferable to SPV and SVV because it is measured directly from the arterial pressure tracing and uses more advanced digital software [59]. Despite limitations in the use of dynamic indices and the inability to assess global ventricular function, SPV, PPV and SVV are currently the most precise predictors of fluid responsiveness [59], and their use does not require any specific training or the physical presence of the clinician during measurements.

In a recent study from Japan, SVV was compared with CVP and pulmonary artery diastolic pressure as estimates of the right and left ventricular preload in patients undergoing renal transplantation. As expected, SVV better predicted volume responsiveness [60]. A retrospective study from 2014 questioned whether SVV can be an alternative to CVP in kidney transplant recipients [73].

An overview of studies monitoring and targeting fluid therapy in kidney transplantation and their main 


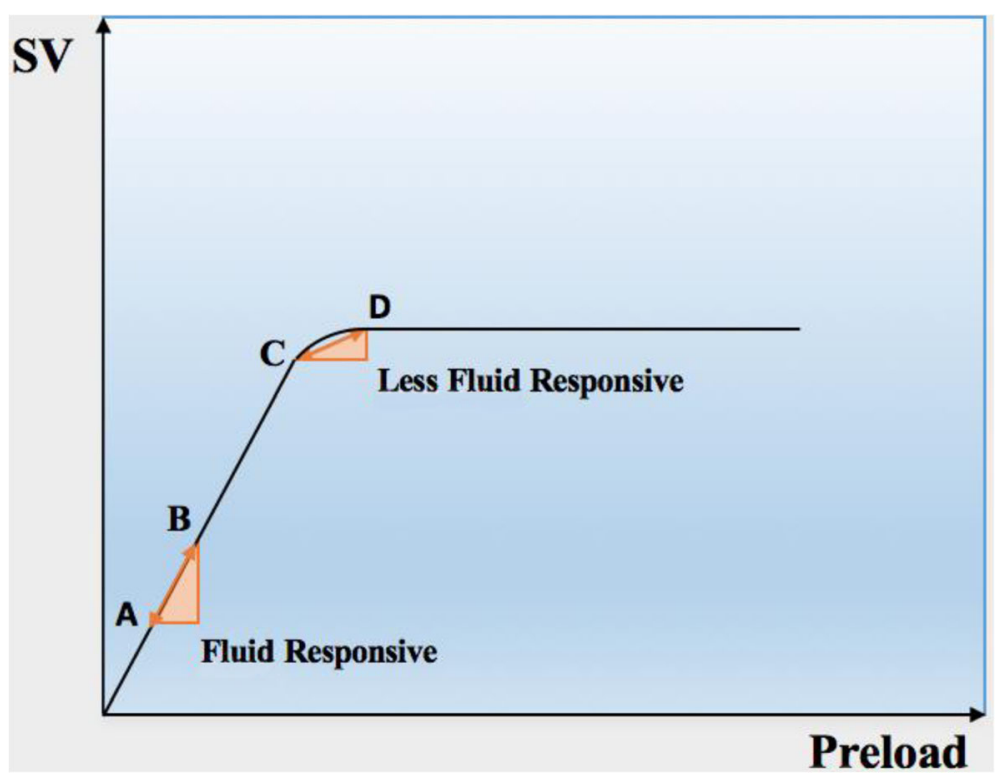

Fig. 3 Frank-Starling curve of preload against left ventricular stroke volume (SV), demonstrating the change in SV induced by cyclic positivepressure ventilation ( $A \leftrightarrow B$ and $C \leftrightarrow D$ ). The starting position on the curve indicates the level of variation possible in the SV after an increase in the preload. Once the patient ascends the curve $(A \rightarrow C)$, fluid responsiveness decreases in response to mechanical ventilation $(C \leftrightarrow D)$

outcomes is presented in Table 1. Most trials have been retrospective cohort studies. Errors due to bias and confounding variables are common and likely affect the results obtained using this study design. More robust clinical trials are necessary to better understand fluid management in kidney recipients.

\section{Flow-directed fluid strategy: a more tailored approach than goal-directed fluid therapy?}

Accumulating evidence supports the concept that fluid therapy should be individualized and based on dynamic indices of the intravascular volume. Conventional monitoring does not provide sufficient information for this approach, but novel technologies may allow titration of therapeutic interventions to ensure that oxygen delivery matches tissue need. One approach using dynamic indices has been goal-directed therapy (GDT). Goal-directed therapy decreased postoperative complications, hospital length of stay, mortality and hospital costs in high-risk surgical patients [17-19]. However, Pearse et al. [74] found no decrease in mortality after use of a CO-guided hemodynamic therapy algorithm compared with usual care. Goal-directed therapy protocols are often associated with an increased infusion volume, and often include significantly more colloids than crystalloids [75]. A factor that needs to be discussed in fluid management is not only the total amount of fluid infused but how, when and to which patient the volume is administered. There are no studies of GDT in kidney transplantation.

In contrast to GDT, which is guided by "goals", flowdirected therapy dictates fluid administration based on "triggers" [62]. The triggers indicate that the clinical state has fallen below an acceptable level and may benefit from increased volume with an increase in $\mathrm{CO}$. It does not aim for a higher than normal target, but rather is based on the clinical impression that the flow is inadequate for tissue needs and asks whether a given volume increased flow [62]. The change in $\mathrm{CO}$ is used as an indicator of the effectiveness of the therapy and not as the primary objective [62]. Thus, when the patient reaches the plateau of the Frank-Starling curve and the SV does not show a change after a fluid bolus, volume expansion is no longer the therapy of choice. Disregard for the status of fluid responsiveness before administering fluids can lead to the unnecessary delivery of fluids, even in GDT protocols. We advocate a flow-directed responsive protocol to be used in the management of perioperative fluid in kidney transplantation. Noninvasive $\mathrm{CO}$ monitoring is used to measure perfusion and assess fluid responsiveness when clinically indicated. After a volume is given (500 $\mathrm{ml}$ of crystalloid) the response of $\mathrm{CO}$ is checked. A $15 \%$ increase in CO with a CVP rise of at least $2 \mathrm{mmHg}$ constitutes a positive response. When there is no appropriate response other therapies should be chosen (i.e., vasopressor and/or inotropic therapy to treat hypotension).

\section{Conclusions}

By optimizing perioperative hemodynamic management in kidney transplantation, we hopefully can improve patient and kidney outcomes. The most recent studies of fluid therapy in the perioperative setting provide more 
Table 1 Monitoring and targeting of fluid therapy in kidney transplantation and the main outcomes

\begin{tabular}{|c|c|c|c|c|c|c|}
\hline Reference & Year & $\begin{array}{l}\text { Type of } \\
\text { donor }\end{array}$ & Study design & $\begin{array}{l}\text { Number } \\
\text { of } \\
\text { patients }\end{array}$ & Study group and aim & Main outcomes \\
\hline $\begin{array}{l}\text { Srivastava } \\
\text { et al. [66] }\end{array}$ & 2015 & Living & $\begin{array}{l}\text { Prospective } \\
\text { nonrandomized } \\
\text { control }\end{array}$ & $\begin{array}{l}110 \\
\text { Study, } \\
104 \\
\text { control }\end{array}$ & $\begin{array}{l}\text { Intraoperative fluid management TED-guided } \\
\text { vs CVP-guided (historical controls) }\end{array}$ & $\begin{array}{l}\text { Same rate of immediate graft functions } \\
\text { in both groups. Less amount of fluid ano } \\
\text { less postoperative complications in TED- } \\
\text { guided group }\end{array}$ \\
\hline $\begin{array}{l}\text { Aulakh et } \\
\text { al. [27] }\end{array}$ & 2015 & Living & Retrospective & 100 & CVP $>12 \mathrm{mmHg}$ vs CVP $<12 \mathrm{mmHg}$ & $\begin{array}{l}\text { Good early graft function if } \mathrm{CVP}=12 \\
\mathrm{mmHg}\end{array}$ \\
\hline $\begin{array}{l}\text { Aulakh et } \\
\text { al. [27] }\end{array}$ & 2015 & Living & Retrospective & 100 & MAP $>100 \mathrm{mmHg}$ vs MAP $<100 \mathrm{mmHg}$ & $\begin{array}{l}\text { Good early graft function if MAP }>95 \\
\mathrm{mmHg}\end{array}$ \\
\hline $\begin{array}{l}\text { Toyoda et } \\
\text { al. [60] }\end{array}$ & 2015 & Living & $\begin{array}{l}\text { Prospective } \\
\text { observational }\end{array}$ & 31 & $\begin{array}{l}\text { SW Vs CVP Vs DPAP as an estimate of } \\
\text { RVEDVI in the same study group }\end{array}$ & SW is a better indicator of preload \\
\hline $\begin{array}{l}\text { Chin et al. } \\
\text { [73] }\end{array}$ & 2014 & No data & Retrospective & 635 & $\begin{array}{l}\text { Ability of SW to predict CVP in the same } \\
\text { study group }\end{array}$ & $\begin{array}{l}\text { SW of } 6 \% \text { as an alternative to CVP of } 8 \\
\mathrm{mmHg}\end{array}$ \\
\hline $\begin{array}{l}\text { Gingell- } \\
\text { Littlejohn } \\
\text { et al. [28] }\end{array}$ & 2013 & No data & Observational & 149 & Effect of MAP on DGF & MAP $<70 \mathrm{mmHg}$ associated with DGF \\
\hline $\begin{array}{l}\text { Campos } \\
\text { et al. [4] }\end{array}$ & 2012 & No data & Retrospective & 1966 & Effect of MAP and CVP on graft function & $\begin{array}{l}\text { Greater graft survival associated with } \\
\text { MAP } \geq 93 \mathrm{mmHg} \text {. Perioperative fluid } \\
\text { administration }<2500 \mathrm{ml} \text { associated with } \\
\text { greater graft survival, whereas CVP } \geq 11 \\
\text { mmHg associated with high rates of ARE } \\
\text { and chronic graft dysfunction }\end{array}$ \\
\hline $\begin{array}{l}\text { Bacchi et } \\
\text { al. [37] }\end{array}$ & 2010 & Deceased & Observational & 155 & Correlation of CVP with DGF & $\begin{array}{l}\text { CVP } \leq 8 \mathrm{mmHg} \text { correlates with DGF. } \\
\text { Fluid input } \leq 2.25 \mathrm{~L} \text { correlates with DGF }\end{array}$ \\
\hline $\begin{array}{l}\text { Othman } \\
\text { et al. [7] }\end{array}$ & 2010 & Living & Randomized & 40 & $\begin{array}{l}\text { Constant infusion rate of } \mathrm{NaCl} 0.9 \% \text { at } 10-12 \\
\mathrm{ml} / \mathrm{kg} / \mathrm{h} \text { vs CVP at } 5 \mathrm{mmHg} \text { during } \\
\text { preischemia time. Post ischemia, the aim was } \\
\text { CVP 8-10 } \mathrm{mmHg} \text { in both groups }\end{array}$ & $\begin{array}{l}\text { CVP target group had better graft } \\
\text { function. Both groups received } \\
\text { approximately } 3 \mathrm{~L} \text { of crystalloids. The } \\
\text { CVP target group required fewer } \\
\text { vasopressors and diuretics and had less } \\
\text { postoperative tissue edema }\end{array}$ \\
\hline $\begin{array}{l}\text { Snoeijs et } \\
\text { al. [5] }\end{array}$ & 2007 & $\begin{array}{l}\text { Deceased } \\
\text { (nonheart- } \\
\text { beating) }\end{array}$ & $\begin{array}{l}\text { Retrospective } \\
\text { observational }\end{array}$ & 177 & $\begin{array}{l}\text { Correlation of hemodynamic data with PNF } \\
\text { of the graft }\end{array}$ & $\begin{array}{l}\text { Average CVP }<6 \mathrm{mmHg} \text { and MAP }<110 \\
\mathrm{mmHg} \text { were significant predictors of } \\
\text { PNF. Preoperative diastolic BP }<80 \\
\text { mmHg was associated with PNF }\end{array}$ \\
\hline $\begin{array}{l}\text { Ferris et } \\
\text { al. [30] }\end{array}$ & 2003 & $\begin{array}{l}\text { Deceased } \\
\text { and living }\end{array}$ & Retrospective & 77 & $\begin{array}{l}<25 \% \text { decline in CVP vs } 25-50 \% \text { decline in } \\
\text { CVP vs }>50 \% \text { decline in CVP in the } \\
\text { immediate post-transplantation period }\end{array}$ & $\begin{array}{l}\text { Neither absolute CVP nor \% drop in CVP } \\
\text { appeared to influence the rate on ATN. } \\
\text { Reperfusion injury or related effects may } \\
\text { be responsible for the CVP drop. No } \\
\text { influence of volume of fluids infused on } \\
\text { occurrence of ATN }\end{array}$ \\
\hline $\begin{array}{l}\text { Tóth et al. } \\
\text { [11] }\end{array}$ & 1998 & Deceased & Prospective & 121 & $\begin{array}{l}\text { Correlation of hemodynamic data with } \\
\text { nonfunctioning grafts vs delayed graft } \\
\text { function vs good graft function }\end{array}$ & $\begin{array}{l}\text { Good graft function group had higher } \\
\text { MAP }(108 \pm 26 \mathrm{mmHg})\end{array}$ \\
\hline $\begin{array}{l}\text { Thomsen } \\
\text { et al. [8] }\end{array}$ & 1987 & $\begin{array}{l}\text { Deceased } \\
\text { and living } \\
(51 \text { vs 10) }\end{array}$ & $\begin{array}{l}\text { Prospective } \\
\text { nonrandomized } \\
\text { control }\end{array}$ & $\begin{array}{l}61 \text { (30 in } \\
\text { group I, } \\
31 \text { in } \\
\text { group II) }\end{array}$ & CVP not measured vs CVP kept $>5 \mathrm{cmH}_{2} \mathrm{O}$ & $\begin{array}{l}\text { Onset of graft function: Group I, 30\%; } \\
\text { Group II, } 62 \%\end{array}$ \\
\hline $\begin{array}{l}\text { Carlier et } \\
\text { al. [10] }\end{array}$ & 1982 & Deceased & $\begin{array}{l}\text { Prospective } \\
\text { observational }\end{array}$ & 120 & $\begin{array}{l}\text { Mean PAP } \leq 20 \mathrm{mmHg} \text { and diastolic PAP } \leq \\
15 \mathrm{mmHg} \text { vs mean PAP }>20 \mathrm{mmHg} \text { and } \\
\text { DPAP }>15 \mathrm{mmHg}\end{array}$ & $\begin{array}{l}36 \% \text { of ATN in Group I vs only } 6 \% \text { in } \\
\text { Group II }\end{array}$ \\
\hline
\end{tabular}

ARE acute renal failure, $A T N$ acute tubular necrosis, $B P$ blood pressure, CVP central venous pressure, DGF delayed graft function, DPAP diastolic pulmonary artery pressure, MAP mean arterial pressure, $P N F$ primary nonfunction, $P A P$ pulmonary artery pressure, RVEDVI right ventricular end-diastolic pressure, SVV stroke volume variation, TED transesophageal Doppler

questions than answers and challenge faith in traditional concepts. Effective perioperative fluid administration in kidney transplantation remains a black box, reinforced by the fact that fluid requirements are highly variable among patients and surgical procedures and the assessment of an individual patient's intravascular volume remains challenging. It is unlikely that there will be a standardized all-inclusive algorithm, and a more highly 
individualized evidence-based approach adapted to each patient's physiological needs and responses to volume and pharmacological therapy might be more helpful.

Prospective comparative clinical studies are warranted to better understand the use of dynamic analyses of flow parameters for optimal fluid management in specific patient populations such as kidney transplant patients, who often have impaired cardiovascular physiology and reduced hemodynamic autoregulation due to end-stage kidney disease.

\begin{abstract}
Abbreviations
AKI: Acute kidney injury; ATN: Acute tubular necrosis; BP: Blood pressure; CO: Cardiac output; CVP: Central venous pressure; DGF: Delayed graft function; GDT: Goal-directed therapy; HR: Heart rate; LV: Left ventricle; MAP: Mean arterial pressure; PAP: Pulmonary artery pressure; PPV: Pulse pressure variation; RV: Right ventricle; RVEDVI: Right ventricular end-diastolic volume index; SPV: Systolic pressure variation; SV: Stroke volume; SW: Stroke volume variation; TED: Transesophageal Doppler; TEE: Transesophageal echocardiography; UOP: Urine output
\end{abstract}

\section{Acknowledgements}

None.

\section{Funding}

None.

\section{Availability of data and materials}

Not applicable.

\section{Authors' contributions}

MHCF wrote the manuscript. TS made substantial contributions to conception and design of this article. SM was involved in revising the manuscript critically for important intellectual content. $\mathrm{RH}$ made substantial contributions to conception and design of this article. All authors have given final approval of the version to be published and agreed to be accountable for all aspects of the work in ensuring that questions related to the accuracy or integrity of any part of the work are appropriately investigated and resolved.

\section{Ethics approval and consent to participate}

Not applicable.

\section{Consent for publication}

Not applicable.

\section{Competing interests}

The authors declare that they have no competing interests.

\section{Publisher's Note}

Springer Nature remains neutral with regard to jurisdictional claims in published maps and institutional affiliations.

\section{Author details}

'Department of Anesthesia, Royal Victoria Hospital, 1001 Decarie Blvd, Montreal, QC H4A 3J1, Canada. ${ }^{2}$ Department of Critical Care Medicine, Royal Victoria Hospital, 1001 Decarie Blvd, Montreal, QC H4A 3J1, Canada.

Received: 5 June 2017 Accepted: 21 December 2017

Published online: 25 January 2018

\section{References}

1. Schnuelle P, Johannes van der Woude F. Perioperative fluid management in renal transplantation: a narrative review of the literature. Transpl Int. 2006; 19(12):947-59.

2. Halloran PF, Hunsicker LG. Delayed graft function: state of the art, November 10-11, 2000. Summit meeting, Scottsdale, Arizona, USA. Am J Transplant. 2001;1(2):115-20.
3. Yarlagadda SG, Coca SG, Formica Jr RN, Poggio ED, Parikh CR. Association between delayed graft function and allograft and patient survival: a systematic review and meta-analysis. Nephrol Dial Transplant. 2009;24(3):1039-47.

4. Campos L, Parada B, Furriel F, Castelo D, Moreira P, Mota A. Do intraoperative hemodynamic factors of the recipient influence renal graft function? Transplant Proc. 2012;44(6):1800-3.

5. Snoeijs MG, Wiermans B, Christiaans MH, van Hooff JP, Timmerman BE, Schurink GW, et al. Recipient hemodynamics during non-heart-beating donor kidney transplantation are major predictors of primary nonfunction. Am J Transplant. 2007;7(5):1158-66.

6. Yee J, Parasuraman R, Narins RG. Selective review of key perioperative renalelectrolyte disturbances in chronic renal failure patients. Chest. 1999;115(5 Suppl):149S-57S.

7. Othman MM, Ismael AZ, Hammouda GE. The impact of timing of maximal crystalloid hydration on early graft function during kidney transplantation. Anesth Analg. 2010;110(5):1440-6.

8. Thomsen HS, Lokkegaard H, Munck O. Influence of normal central venous pressure on onset of function in renal allografts. Scand J Urol Nephrol. 1987; 21(2):143-5.

9. Carlier M, Squifflet JP, Pirson Y, Decocq L, Gribomont B, Alexandre GP. Confirmation of the crucial role of the recipient's maximal hydration on early diuresis of the human cadaver renal allograft. Transplantation. 1983; 36(4):455-6.

10. Carlier M, Squifflet JP, Pirson Y, Gribomont B, Alexandre GP. Maximal hydration during anesthesia increases pulmonary arterial pressures and improves early function of human renal transplants. Transplantation. 1982; 34(4):201-4

11. Tóth M, Reti V, Gondos T. Effect of recipients' peri-operative parameters on the outcome of kidney transplantation. Clin Transplant. 1998;12(6):511-7.

12. Chappell D, Jacob M, Hofmann-Kiefer $K$, Conzen $P$, Rehm M. A rational approach to perioperative fluid management. Anesthesiology. 2008;109(4):723-40.

13. Magder S. How to use central venous pressure measurements. Curr Opin Crit Care. 2005;11(3):264-70.

14. Magder S. Current tools for assessing heart function and perfusion adequacy. Curr Opin Crit Care. 2014;20(3):294-300.

15. Marik PE, Cavallazzi R. Does the central venous pressure predict fluid responsiveness? An updated meta-analysis and a plea for some common sense. Crit Care Med. 2013:41(7):1774-81.

16. Schindler AW, Marx G. Evidence-based fluid management in the ICU. Curr Opin Anaesthesiol. 2016;29(2):158-65.

17. Gurgel ST, do Nascimento Jr P. Maintaining tissue perfusion in high-risk surgical patients: a systematic review of randomized clinical trials. Anesth Analg. 2011;112(6):1384-91.

18. Hamilton MA, Cecconi M, Rhodes A. A systematic review and meta-analysis on the use of preemptive hemodynamic intervention to improve postoperative outcomes in moderate and high-risk surgical patients. Anesth Analg. 2011:112(6):1392-402.

19. Poeze M, Greve JW, Ramsay G. Meta-analysis of hemodynamic optimization: relationship to methodological quality. Crit Care. 2005;9(6):R771-9.

20. Yarlagadda SG, Coca SG, Garg AX, Doshi M, Poggio E, Marcus RJ, et al. Marked variation in the definition and diagnosis of delayed graft function: a systematic review. Nephrol Dial Transplant. 2008;23(9):2995-3003.

21. Decruyenaere $P$, Decruyenaere $A$, Peeters $P$, Vermassen F. A single-center comparison of 22 competing definitions of delayed graft function after kidney transplantation. Ann Transplant. 2016:21:152-9.

22. Helfer MS, Vicari AR, Spuldaro F, Goncalves LF, Manfro RC. Incidence, risk factors, and outcomes of delayed graft function in deceased donor kidney transplantation in a Brazilian center. Transplant Proc. 2014;46(6):1727-9.

23. Perico N, Cattaneo D, Sayegh MH, Remuzzi G. Delayed graft function in kidney transplantation. Lancet. 2004;364(9447):1814-27.

24. Gentil MA, Castro de la Nuez P, Gonzalez-Corvillo C, de Gracia MC, Cabello M, Mazuecos MA, et al. Non-heart-beating donor kidney transplantation survival is similar to donation after brain death: comparative study with controls in a regional program. Transplant Proc. 2016;48(9):2867-70.

25. Massberg S, Messmer K. The nature of ischemia/reperfusion injury. Transplant Proc. 1998;30(8):4217-23.

26. Goldfarb CR, Srivastava NC, Grotas AB, Ongseng F, Nagler HM. Radionuclide imaging in urology. Urol Clin North Am. 2006;33(3):319-28.

27. Aulakh NK, Garg K, Bose A, Aulakh BS, Chahal HS, Aulakh GS. Influence of hemodynamics and intra-operative hydration on biochemical outcome of renal transplant recipients. J Anaesthesiol Clin Pharmacol. 2015;31(2):174-9. 
28. Gingell-Littlejohn M, Koh H, Aitken E, Shiels PG, Geddes C, Kingsmore D, et al. Below-target postoperative arterial blood pressure but not central venous pressure is associated with delayed graft function. Transplant Proc. 2013:45(1):46-50.

29. Morita K, Seki T, Nonomura K, Koyanagi T, Yoshioka M, Saito H. Changes in renal blood flow in response to sympathomimetics in the rat transplanted and denervated kidney. Int J Urol. 1999;6(1):24-32.

30. Ferris RL, Kittur DS, Wilasrusmee C, Shah G, Krause E, Ratner L. Early hemodynamic changes after renal transplantation: determinants of low central venous pressure in the recipients and correlation with acute renal dysfunction. Med Sci Monit. 2003;9(2):CR61-6.

31. Bastin AJ, Ostermann M, Slack AJ, Diller GP, Finney SJ, Evans TW. Acute kidney injury after cardiac surgery according to Risk/Injury/Failure/Loss/Endstage, Acute Kidney Injury Network, and Kidney Disease: Improving Global Outcomes classifications. J Crit Care. 2013;28(4):389-96.

32. Hoste EA, Bagshaw SM, Bellomo R, Cely CM, Colman R, Cruz DN, et al. Epidemiology of acute kidney injury in critically ill patients: the multinational AKI-EPI study. Intensive Care Med. 2015;41(8):1411-23.

33. Ostermann M, Chang R, Riyadh ICUPUG. Correlation between the AKI classification and outcome. Crit Care. 2008;12(6):R144.

34. Lewington AJ, Cerda J, Mehta RL. Raising awareness of acute kidney injury: a global perspective of a silent killer. Kidney Int. 2013;84(3):457-67.

35. Goldberg RJ, Weng FL, Kandula P. Acute and chronic allograft dysfunction in kidney transplant recipients. Med Clin North Am. 2016;100(3):487-503.

36. Imig JD, Ryan MJ. Immune and inflammatory role in renal disease. Compr Physiol. 2013;3(2):957-76.

37. Bacchi G, Buscaroli A, Fusari M, Neri L, Cappuccilli ML, Carretta E, et al. The influence of intraoperative central venous pressure on delayed graft function in renal transplantation: a single-center experience. Transplant Proc. 2010;42(9):3387-91.

38. Ince $\mathrm{C}$. The rationale for microcirculatory guided fluid therapy. Curr Opin Crit Care. 2014;20(3):301-8.

39. Hamilton-Davies C, Mythen MG, Salmon JB, Jacobson D, Shukla A, Webb AR. Comparison of commonly used clinical indicators of hypovolaemia with gastrointestinal tonometry. Intensive Care Med. 1997;23(3):276-81.

40. Cocchi MN, Kimlin E, Walsh M, Donnino MW. Identification and resuscitation of the trauma patient in shock. Emerg Med Clin North Am. 2007;25(3):623-42. vii.

41. Curry FR. Atrial natriuretic peptide: an essential physiological regulator of transvascular fluid, protein transport, and plasma volume. J Clin Invest. 2005; 115(6):1458-61.

42. Jacob M, Chappell D, Becker BF. Regulation of blood flow and volume exchange across the microcirculation. Crit Care. 2016;20(1):319.

43. Norberg A, Hahn RG, Li H, Olsson J, Prough DS, Borsheim E, et al. Population volume kinetics predicts retention of $0.9 \%$ saline infused in awake and isoflurane-anesthetized volunteers. Anesthesiology. 2007;107(1):24-32.

44. Bayliss WM. On the local reactions of the arterial wall to changes of internal pressure. J Physiol. 1902;28(3):220-31.

45. Harper AM. Autoregulation of cerebral blood flow: influence of the arterial blood pressure on the blood flow through the cerebral cortex. J Neurol Neurosurg Psychiatry. 1966;29(5):398-403.

46. Walsh M, Devereaux PJ, Garg AX, Kurz A, Turan A, Rodseth RN, et al. Relationship between intraoperative mean arterial pressure and clinical outcomes after noncardiac surgery: toward an empirical definition of hypotension. Anesthesiology. 2013;119(3):507-15.

47. Asfar P, Meziani F, Hamel JF, Grelon F, Megarbane B, Anquel N, et al. High versus low blood-pressure target in patients with septic shock. N Engl J Med. 2014;370(17):1583-93.

48. Pajek J, Skoberne A, Sosteric K, Adlesic B, Leskosek B, Bucar Pajek M, et al. Non-inferiority of creatinine excretion rate to urinary L-FABP and NGAL as predictors of early renal allograft function. BMC Nephrol. 2014;15:117.

49. Lemmens HJ. Kidney transplantation: recent developments and recommendations for anesthetic management. Anesthesiol Clin North America. 2004;22(4):651-62.

50. Holte K, Sharrock NE, Kehlet H. Pathophysiology and clinical implications of perioperative fluid excess. Br J Anaesth. 2002;89(4):622-32.

51. De Gasperi A, Narcisi S, Mazza E, Bettinelli L, Pavani M, Perrone L, et al. Perioperative fluid management in kidney transplantation: is volume overload still mandatory for graft function? Transplant Proc. 2006;38(3):807-9.

52. Gustafsson UO, Hausel J, Thorell A, Ljungqvist O, Soop M, Nygren J, et al. Adherence to the enhanced recovery after surgery protocol and outcomes after colorectal cancer surgery. Arch Surg. 2011;146(5):571-7.
53. Prowle JR, Echeverri JE, Ligabo EV, Ronco C, Bellomo R. Fluid balance and acute kidney injury. Nat Rev Nephrol. 2010;6(2):107-15.

54. Magder S. Volume and its relationship to cardiac output and venous return. Crit Care. 2016:20:271.

55. Sandham JD, Hull RD, Brant RF, Knox L, Pineo GF, Doig CJ, et al. A randomized, controlled trial of the use of pulmonary-artery catheters in high-risk surgical patients. N Engl J Med. 2003;348(1):5-14.

56. Kearney TJ, Shabot MM. Pulmonary artery rupture associated with the Swan-Ganz catheter. Chest. 1995;108(5):1349-52.

57. Bossert T, Gummert JF, Bittner HB, Barten M, Walther T, Falk V, et al. SwanGanz catheter-induced severe complications in cardiac surgery: right ventricular perforation, knotting, and rupture of a pulmonary artery. J Card Surg. 2006;21(3):292-5.

58. Jacka MJ, Cohen MM, To T, Devitt JH, Byrick R. Pulmonary artery occlusion pressure estimation: how confident are anesthesiologists? Crit Care Med. 2002;30(6):1197-203

59. Marik PE, Cavallazzi R, Vasu T, Hirani A. Dynamic changes in arterial waveform derived variables and fluid responsiveness in mechanically ventilated patients: a systematic review of the literature. Crit Care Med. 2009;37(9):2642-7.

60. Toyoda D, Fukuda M, Iwasaki R, Terada T, Sato N, Ochiai R, et al. The comparison between stroke volume variation and filling pressure as an estimate of right ventricular preload in patients undergoing renal transplantation. J Anesth. 2015;29(1):40-6.

61. Marik PE, Baram M, Vahid B. Does central venous pressure predict fluid responsiveness? A systematic review of the literature and the tale of seven mares. Chest. 2008;134(1):172-8.

62. Magder S. Flow-directed vs. goal-directed strategy for management of hemodynamics. Curr Opin Crit Care. 2016;22(3):267-73.

63. Braunwald E, Ross Jr J, Sonnenblick EH. Mechanisms of contraction of the normal and failing heart. N Engl J Med. 1967;277(15):794-800. contd.

64. Ait Mou Y, Bollensdorff C, Cazorla O, Magdi Y, de Tombe PP. Exploring cardiac biophysical properties. Glob Cardiol Sci Pract. 2015;2015:10.

65. Thiel SW, Kollef MH, Isakow W. Non-invasive stroke volume measurement and passive leg raising predict volume responsiveness in medical ICU patients: an observational cohort study. Crit Care. 2009;13(4):R111.

66. Srivastava D, Sahu S, Chandra A, Tiwari T, Kumar S, Singh PK. Effect of intraoperative transesophageal Doppler-guided fluid therapy versus central venous pressure-guided fluid therapy on renal allograft outcome in patients undergoing living donor renal transplant surgery: a comparative study. J Anesth. 2015;29(6):842-9.

67. Perel A, Habicher M, Sander M. Bench-to-bedside review: functional hemodynamics during surgery - should it be used for all high-risk cases? Crit Care. 2013;17(1):203.

68. Clement RP, Vos JJ, Scheeren TWL. Minimally invasive cardiac output technologies in the ICU: putting it all together. Curr Opin Crit Care. 2017;23(4):302-9.

69. Joosten A, Desebbe O, Suehiro K, Murphy LS, Essiet M, Alexander B, et al. Accuracy and precision of non-invasive cardiac output monitoring devices in perioperative medicine: a systematic review and meta-analysisdagger. $\mathrm{Br}$ J Anaesth. 2017;118(3):298-310.

70. Michard F, Teboul JL. Using heart-lung interactions to assess fluid responsiveness during mechanical ventilation. Crit Care. 2000;4(5):282-9.

71. Perner A, Faber T. Stroke volume variation does not predict fluid responsiveness in patients with septic shock on pressure support ventilation. Acta Anaesthesiol Scand. 2006;50(9):1068-73.

72. Richter HP, Petersen C, Goetz AE, Reuter DA, Kubitz JC. Detection of right ventricular insufficiency and guidance of volume therapy are facilitated by simultaneous monitoring of static and functional preload parameters. J Cardiothorac Vasc Anesth. 2011;25(6):1051-5.

73. Chin JH, Jun IG, Lee J, Seo H, Hwang GS, Kim YK. Can stroke volume variation be an alternative to central venous pressure in patients undergoing kidney transplantation? Transplant Proc. 2014;46(10):3363-6.

74. Pearse RM, Harrison DA, MacDonald N, Gillies MA, Blunt M, Ackland G, et al. Effect of a perioperative, cardiac output-guided hemodynamic therapy algorithm on outcomes following major gastrointestinal surgery: a randomized clinical trial and systematic review. JAMA. 2014;311(21):2181-90.

75. Mayer J, Boldt J, Mengistu AM, Rohm KD, Suttner S. Goal-directed intraoperative therapy based on autocalibrated arterial pressure waveform analysis reduces hospital stay in high-risk surgical patients: a randomized, controlled trial. Crit Care. 2010;14(1):R18. 